\title{
Percutaneous release of trigger finger without local anaesthesia as an outpatient procedure
}

\author{
Malviya V.K. ${ }^{1}$, Soni R.K. ${ }^{2}$ \\ ${ }^{1}$ Dr. Vikas Kumar Malviya, Associate Professor, Department of General Surgery, ${ }^{2}$ Dr. Ram Kripal Soni, Assistant \\ Professor, Department of Orthopedic, Both authors are affiliated with L.N. Medical College, Bhopal, MP, India. \\ Corresponding Author: Dr. Ram Kripal Soni, Assistant Professor, Department of orthopedic, author is affiliated with \\ L.N. Medical College, Bhopal, MP, India. E-mail: ramkesoni@yahoo.co.uk
}

\begin{abstract}
Background: Stenosing tenosynovitis or trigger finger frequently involves the thumb and ring fingers of the dominant hand and more commonly seen in adult female population, in their 5th and 6th decades of life. Method: In this study, 18gauge needle was used for the percutaneous release of trigger finger without any local anaesthesia in 12 patients with prior consent. Results: Highest numbers of patients were in 41-60 years age group (66.7\%). 3 patients (25\%) belong to $20-41$ years age group. Only 1 patient (8.3\%) of age group 61-80 was affected by trigger finger. 7 Patients $(58.3 \%)$ were females and 5 patients $(41.6 \%)$ were males. The most commonly affected finger was the ring $(58.3 \%)$ followed by the middle (33.3\%) and index (8.3\%). Right hand and left hand was affected side in $8(66.6 \%)$ and $4(33.3 \%)$ patients respectively. According to greens classification, Grade II patients were 50\%, grade III $41.6 \%$ and grade IV $8.3 \%$. Average duration of the procedure was 5-7 minutes. There was no evidence of complications. 4 patients experienced mild postoperative pain. In one patient the procedure has to be abandoned as patient could not tolerate the pain. Conclusion: As we do not use local anaesthesia localization of A 1 pulley in trigger finger is much easier for percutaneous release. Therefore, the procedure is more effective and time saving as well.
\end{abstract}

Keywords: Percutaneous release, Trigger Finger, Stenosing tenosynovitis, Without local anaesthesia

\section{Introduction}

Stenosing tenosynovitis commonly known as trigger finger is a common disorder of hand in adults which can cause pain, swelling and locking sensation in the affected finger. It frequently involves the thumb and ring fingers of the dominant hand [1]. It is more commonly seen in adult female population ( $\sim F: M=4: 1)$, in their 5 th and $6^{\text {th }}$ decades of life [2]. The lifetime prevalence of trigger fingers among nondiabetics is approximately $2.6 \%$ [3].

The primary pathology is thickening of the A1 pulley with resultant entrapment of the flexor tendon, thus forming a triggering mechanism [4]. With this pathology of size mismatch between the flexor tendon and the first annular (A-1) pulley, catching or locking of finger occurs during the flexion. If left untreated, this may cause flexion contracture of the proximal interphalangeal joints [5]. The main treatment option of trigger finger in early stages is conservative

Manuscript Received: $6^{\text {th }}$ August 2019

Reviewed: $16^{\text {th }}$ August 2019

Author Corrected: $24^{\text {th }}$ August 2019

Accepted for Publication: 29 $9^{\text {th }}$ August 2019 management. Steroid and local anesthetic injection, and splint application are recommended in the acute stage [6-10]. Conservative treatment involves a high failure rate, requiring repetitive injections [11-12]. When conservative treatment fails; open release of the A1pulley is recommended [12-14]. In diabetic patients trigger finger often is less responsive to conservative measures. Lorthioir was the first person to describe percutaneous release technique using a thin tenotome [15]. Various methods using several instruments were reported afterwards [16-20].

In this study, we used an18-gauge needle for the percutaneous release of trigger finger without any local anaesthesia in cooperative patient with prior consent. We treated 12 patients of trigger fingers with this method as an outpatient procedure. Satisfactory results were obtained in 11 patients. Infiltration of local anaesthesia obscures the local anatomy around the pulley. There has not been any study in the English literature to our knowledge involving percutaneous trigger finger release without local anesthetic agent 


\section{Original Research Article}

previously. Hypothesis was made that our technique would result in much more accurate localization of A -1 Pulley which would decrease the time and cost. We therefore recommend this convenient, quick and costeffective outpatient procedure with a low complication rate with prior consent in cooperative patients. In this small series in selected patients, the procedure was well tolerated by patients.

\section{Methods}

Place of study: J.K. Hospital associated with L.N. Medical College Bhopal (M.P.).

Type of study: Prospective study

\section{Sampling method: Consecutive}

Sample collection: 12 adult patients with diagnosis of trigger finger were recruited between July 2018 to May 2019 and treated by percutaneous release technique without local anaesthesia.We first counsel the patient and explain exactly what the procedure entails in greater details, including risks and benefits of procedure without local anaesthesia and the informed consent was obtained.

All surgeries were performed in the same manner, at the same facility and by the two surgeons. All the relevant details of patients were tabulated using detailed proforma.

Details of patients like age, sex, type of affected finger, side of upper limb, timing of procedure and complications were recorded. Initial diagnosis of trigger finger was made on the basis of detailed history and clinical examination. In all the cases who given the consent for the procedure without local anaesthesia, this procedure was carried out. All the relevant data were compiled on master chart.

Inclusion criteria: Only adult patients with trigger finger of either sex, who given the consent for procedure without any anaesthesia were included in the study. All the patients had single trigger finger involvement.

Exclusion Criteria: Patients who refused this procedure without local anaesthesia were excluded from this study. Early stage patients with grade I of Greens classification of trigger finger were also excluded from study as these patients are usually treated with conservative management. Patients with trigger thumb were also excluded due to possible risk of digital nerve injury. Patient with more than one triggerfingers involvement in the same hand were excluded from the study.

Statistical Methods: Results were shown in tables, comparing their numbers and percentages by scientific calculator.

\section{Ethical Permission: Yes}

Procedure: This procedure was carried out in the outpatient department. Palmer skin was cleaned and the digit was hyperextended.To facilitate the hyperextension of involved digit, a small sterile folded towel was kept under the hand which makes it easier to palpate and localize the A 1 Pulley.

This pulley is along the distal transverse palmer crease opposite the metacarpophalangeal joint of the digit. Clear under-standing of the location of the A1 pulley is key to successfully performing a percutaneous trigger release. An 18-gauge hypodermic needle tip is inserted through the skin at the proximal extent of the A1 pulley and into the flexor tendon.

Needle placement is confirmed by observing the paradoxical movement of the needle on gentle flexion of the digit. The needle tip is then withdrawn until it is no longer in the flexor tendon. With the bevel of the needle in the flexor sheath, the pulley is divided by a gentle but firm lifting action, from distal to proximal.

Complete release is ensured at the end of the procedure by asking the patient to flex and extend the finger and was found to be moving freely without triggering or any restriction in finger extension. Because no incision is made, no stitches are needed after the procedure.

Pressure dressing is applied at the puncture site and the patient is advised to keep hand elevated for next 24 hours. Patients were also advised to use night splint for next two weeks.

This is particularly important in patients where the patients has grade IV locked trigger finger. Patient was then seen next day to change the pressure dressing to a simple local adhesive dressing. Patient was than seen in a week's times to remove the dressing.

Subsequent follow-up for 3 months was arranged.All patients were reviewed at 3 months and subjective and objective assessment was made for patient's satisfaction and for and local complications or recurrence of symptoms respectively. 


\section{Results}

The aim of this study is to find out the efficacy of this percutaneous trigger finger release technique using 18 gaugeneedle without any local anaesthesia. After analysis of the patient's data, following observations and results were obtained.

Table-1: Age wise distribution.

\begin{tabular}{|c|c|c|}
\hline Age group (years) & Number of patients & \% \\
\hline $20-40$ & 3 & 25 \\
\hline $41-60$ & 8 & 66.7 \\
\hline $61-80$ & 1 & 8.3 \\
\hline
\end{tabular}

A total of 12 patients with 12 trigger fingers were included in present study. Highest number of patients belonged to 41-60 years age group (66.7\%). 3 patients (25\%) to 20-41 years age group. Only 1 patient (8.3\%) of age group 61-80 was affected by trigger finger in the study.

Table-2: Sex wise distribution.

\begin{tabular}{|c|c|c|}
\hline & Number of patients & \% \\
\hline Male & 5 & 41.6 \\
\hline Female & 7 & 58.3 \\
\hline & 12 & \\
\hline
\end{tabular}

About 7 (58.3\%) were females and 5 (41.6\%) were males.

Table-3: Type of affected finger.

\begin{tabular}{|c|c|c|}
\hline & Number of patients & \% \\
\hline Index finger & 1 & 33.3 \\
\hline Middle finger & 4 & 58.3 \\
\hline Ring finger & 7 & \\
\hline
\end{tabular}

The most commonly affected finger was the ring finger followed by the middle finger and index. No patient in our study presented with little finger stenosing tenosynovitis. Patient affected with more than one trigger finger were excluded.

Table-4: Side of upper limb with affected finger.

\begin{tabular}{|c|c|c|}
\hline & Number of patients & \% \\
\hline Right & 8 & 66.6 \\
\hline Left & 4 & 33.3 \\
\hline
\end{tabular}

Right hand (66.6\%) was most common affected side. Left hand was affected in $33.3 \%$ patients.

Table -5: Greens classification.

\begin{tabular}{|l|l|c|c|}
\hline & & Number of patients & $\%$ \\
\hline I & Pain/history of catching & 0 & 0 \\
\hline II & Demonstrate catching, but can actively extend the digit & 6 & $50 \%$ \\
\hline III & Demonstrate locking, requiring passive extension & 5 & $41.6 \%$ \\
\hline IV & Fixed flexion contracture & 1 & $8.3 \%$ \\
\hline
\end{tabular}

In our study, trigger finger was classified according to Green classification [2]. Grade II patients were 50\%, grade III $41.6 \%$ and grade IV $8.3 \%$. 
Original Research Article

Table-6: Outcome and complications.

\begin{tabular}{|l|c|c|}
\hline & Number of patients & \% \\
\hline Successful release & 11 & $91.6 \%$ \\
\hline Incomplete release & 1 & $8.3 \%$ \\
\hline Postoperative pain & 4 & $33.3 \%$ \\
\hline
\end{tabular}

All the pts were reviewed at 3 months after the procedure.There was no evidence of digital nerve injury, flexor tendon injury, stiffness of the finger or infection and recurrence. The patients were also inquired about the postoperative pain, 4 out of 12 patients experienced mild postoperative pain lasting for 24 hours. Of the 12 patients, 1 patient had no benefit with this technique as the patients could not tolerate the pain during the procedure resulting in incomplete release of pulley. This patient was operated with percutaneous release under local anaesthesia successfully.

\section{Discussion}

Trigger finger is characterized by the thickening of the tendon sheath and the A1 pulley and sometimes nodule formation on the tendon together with luminal narrowing [21]. The condition has a reported annual incidence of 28 cases per 100000 population, or a lifetime risk of $2.6 \%$ in the general population [22]. This rises to $10 \%$ in patients with diabetes [23]. Secondary trigger finger can be seen in patients with diabetes, gout, renal disease, rheumatoid arthritis and other rheumatic diseases and is associated with a worse prognosis after conservative or surgical management $[24,25]$.

Primary trigger finger occurs most commonly in fifth to sixth decades of life and up to 6 times more frequently in women than men [26-29]. The present study also suggests the middle-aged peoples (41-60) as a most common group $(66.7 \%)$ with female predominance (58.3\%).

All digits can be affected, but the ring finger is most often involved, followed by the thumb and the long, index, and little fingers, in that order [30-31]. More than one trigger digit can be present on the same hand. Triggering of digits in both hands is also common. Present study also shows the ring finger as most commonly affected digit.

Percutaneous release of the A1 pulley in 25 cadaveric study by Pope (1995) revealed full release and resolution of triggering in $90 \%$ of the specimens [32]. Their observation was that the radial digital nerve was within $2-3 \mathrm{~mm}$ of the needle site and suggested that percutaneous techniqueshould not be used in trigger thumb. Therefore in the present study, trigger thumb release was excluded percutaneously in our short series. Several other authors have also indicated that the relative volar position of the digital nerves in the thumb closer to A1 pulley. This clearly increases the risk of injury to digital nerve with close percutaneous technique [33]. Right hand which is dominant side (66.6\%) was most common affected side in our study. Left hand was affected in $33.3 \%$ patients. Patients with trigger finger were classified according to Green classification [2]. Grade I patients who presented with pain and history of catching, were the good candidate for conservative management, therefore were excluded from present study.

Grade II patients who demonstrated the catching, but can actively extend the digit were $50 \%$. Grade III patientswho demonstrated locking, requiring passive extension were $41.6 \%$. Grade IV patients with fixed flexion contracture were $8.3 \%$. Similiarly Niraj ranjeet et al also reported 16 patients (53.3\%) with grade II, 12 patients $(40 \%)$ with grade III and 2 patients $(6.6 \%)$ with grade IV [34].

Conservative treatment of trigger finger which includes injections of steroids, local anesthetics and splint application, is the most commonly used treatment for grade I trigger finger. In patients who did not benefit from conservative treatment, percutaneous release or open surgery is usually recommended.

Bain et al. recommended percutaneous release operation for active and movable trigger fingers and discouraged application of this procedure for locked fingers or those with tenosynovitis [35]. However in our short series we had one patient with grade IV locked ring finger of two months duration. This patient was successfully operated with our technique.

The percutaneous release procedure developed by Eastwood et al. has been popularized with assertions favoring its ease of application and lower cost and complication rates [36]. Percutaneous release is most commonly performed under the local anaesthesia and 


\section{Original Research Article}

with ultrasonography guidance which needs the facility of ultrasonography equipment and availability of radiologist. In the present study, all the cases were performed without local anaesthesia and without sonographic guidance that makes the procedure to be time saving outpatient procedure.

Average duration of the procedure in our study was 5 to 7 minutes. In our technique, we did not use local anesthetic agent therefore clinical land marks and local anatomy was not obscured and was easier to precisely localize the A1 pulley with tip of the needle for percutaneous release which facilitated the procedure to be done in shorter time.

Several techniques for percutaneous release of the A1 pulley have been described with satisfactory results $[15$, 20,28,36]. Advantage of percutaneous release technique avoids the time and expense of an open procedure with the few complications. Percutaneous release technique although, has been practiced by many plastic and orthopedic surgeon, but still there is a reluctance by some surgeons due to the fear of injuring the digital nerves and vessels and the chance of having incomplete release of A1 pulley.

The possible complications of percutaneous release are the risks of digital nerve injury (hypoaesthesia), damage to unseen tendon tissue, delayed tendon rupture, painful scar and recurrence remains with this technique but this risk is much less than with open surgery [37].

In the present study, there was no evidence of digital nerve injury, flexor tendon injury, stiffness of the finger or infection. 4 patients complained of mild postoperative pain. In 11 patients $(91.6 \%)$ patients, this technique without anaesthesia was successful and only one patient had no benefit with this technique as the patients could not tolerate the pain during the procedure resulting in incomplete release of pulley. This patient was operated with percutaneous release under local anaesthesia successfully.

This study clearly shows the effectiveness of close percutaneous release without local anesthetic agent with no significant complications.

All patients tolerated the procedure well.We knowingly selected a small series of patient to test our hypothesis regarding tolerability of the procedure without any anesthetic agent, its effectiveness and the complications. We recommend this procedure in selected cooperative patients as it is safer, more effective, time and cost saving procedure. This study needs to be replicated with a larger series before extrapolating and generalizing its findings.

\section{Conclusion}

Trigger finger is a mechanical problem caused by a mismatch between the relative size of the flexor tendon and A1 pulley. Appropriate treatment is based on understanding of the exact anatomic localization of pulley. Because of precise localization of pulley, we conclude that our technique of percutaneous trigger finger release without local anaesthesia is effective, can be performed with ease, speed and safety in outpatient clinics in selected patients.

\section{What this study adds to existing knowledge?}

There has not been any study in the literature to our knowledge involvingpercutaneous trigger finger release without local anesthetic previously. The present study reports this study of percutaneous trigger finger release without using local anesthetic agent with an 18-gauge needle. This was a very effective and result oriented technique. As the sample size of this study is small, more research work needs to be done in a much larger series with longer follow-up in the future to establish its efficacy.

\section{Author's contribution}

Dr. Ram Kripal Soni: Formulated the aims \& objectives with study design and supervised for study

Dr. Vikas Kumar Malviya: Preparation of the manuscript and Data analysis.

Conflict of interest: None declared.

Funding: Nil, Permission from IRB: Yes

\section{Reference}

1. Bonnici AV, Spencer JD. A survey of 'trigger finger' in adults. J Hand Surg Br. 1988;13(2):202-203. doi: 10. 1016/0266-7681(88)90139-8

2. Green DP, Hotchkiss RN, Pederson WC. Green's Operative Hand Surgery. Elsevier Health Sciences; $4^{\text {th }}$ Edition; 1999. p. 2029

3. Wojahn RD, Foeger NC, Gelberman RH, Calfee RP. Long-term outcomes following a single corticosteroid injection for trigger finger. J Bone Joint Surg Am. 2014;96 (22):1849-1854. doi: 10.2106/JBJS.N.00004. 


\section{Original Research Article}

4. Sampson SP, Badalamente MA, Hurst LC, Seidman

J. Pathobiology of the human A1 pulley in trigger finger. J Hand Surg Am. 1991;16(4):714-721. doi:10. 1016/ 0363-5023(91)90200-u

5. Wolfe, S.W. Tenosynovitis. in: D.P. Green, R.N. Hotchkiss, W.C. Pederson, S.W. Wolfe (Eds.) Green's operative hand surgery. $5^{\text {th }}$ ed. Churchill Livingstone, New York; 2005:2137-2158.

6. Yamada K, Masuko T, Iwasaki N. Rupture of the flexor digitorum profundus tendon after injections of insoluble steroid for a trigger finger. J Hand Surg Eur Vol. 2011; 36 (1):77-78. doi: 10.1177/175319341038 2377.

7. Salim N, Abdullah S, Sapuan J, Haflah NH. Outcome of corticosteroid injection versus physiotherapy in the treatment of mild trigger fingers. J Hand Surg Eur Vol.2012;37(1):27-34.doi:10.1177/1753193411415343. Epub 2011 Aug 4.

8. Kazuki K, Egi T, Okada M, Takaoka K. Clinical outcome of extrasynovial steroid injection for trigger finger. Hand Surg. 2006;11(1-2):1-4. doi:10.1142/S021 8810406003115

9. Pataradool K, Buranapuntaruk T. Proximal phalanx injection for trigger finger: randomized controlled trial. Hand Surg. 2011;16(3):313-317. doi:10.1142/S0218810 411005606

10. Tarbhai K, Hannah S, von Schroeder HP. Trigger finger treatment: a comparison of 2 splint designs. J Hand Surg Am. 2012;37(2):243-9, 249.e1. doi: 10. 1016/j. jhsa.2011.10.038. Epub 2011 Dec 20.

11. Chao M, Wu S, Yan T. The effect of miniscalpelneedle versus steroid injection for trigger thumb release. J Hand Surg Eur Vol. 2009;34(4):522-525. doi: 10. $1177 / 1753193409100961$.

12. Ha KI, Park MJ, Ha CW. Percutaneous release of trigger digits: a technique and results using a specially designed knife. J Bone Joint Surg. 2001;83(1):75-77

13. Ryzewicz M, Wolf JM. Trigger digits: principles, management, and complications. J Hand Surg Am. 2006;31(1):135-146. doi:10.1016/j.jhsa.2005.10.013

14. Gilberts EC, Wereldsma JC. Long-term results of percutaneous and open surgery for trigger fingers and thumbs. Int Surg. 2002; 87(1):48-52.
15. Lorthioir J Jr. Surgical treatment of trigger-finger by a subcutaneous method. J Bone Joint Surg Am. 1958; 40-A(4): 793-795

16. Dierks U, Hoffmann R, Meek MF. Open versus percutaneous release of the A1-pulley for stenosing tendovaginitis: a prospective randomized trial. Tech Hand Up Extrem Surg. 2008; 12 (3): 183-187. doi: 10. 1097/ BTH.0b013e31817f289a.

17. Pavlicný R. [Percutaneous release in the treatment of trigger digits]. Acta Chir Orthop Traumatol Cech. 2010;77(1):46-51.

18. Schramm JM, Nguyen M, Wongworawat MD. The safety of percutaneous trigger finger release. Hand $(\mathrm{N}$ Y). 2008; 3(1):44-6. doi: 10.1007/s1 1552-007-9069-8. Epub 2007 Sep 14.

19. Cebesoy O, Kose KC, Baltaci ET, Isik M. Percutaneous release of the trigger thumb: is it safe, cheap and effective? Int Orthop. 2007; 31(3): 345-349. Epub 2006 Jul 18. DOI: 10.1007/ s00264-0060180-1

20. Tanaka J. Percutaneous trigger finger release. Techniques in hand \& upper extremity surgery. 1999;3 (1): 52-57.

21. Kiliç BA, Kiter AE, Selçuk Y. [The effect of percutaneous trigger finger release on normal anatomic structures and long-term results of the procedure]. Acta Orthop Traumatol Turc. 2002;36(3):256-258.

22. Saldana MJ. Trigger digits: diagnosis and treatment. J Am Acad Orthop Surg. 2001;9(4):246-252.

23. Marcus AM, Culver JE Jr, Hunt TR 3rd. Treating trigger finger in diabetics using excision of the ulnar slip of the flexor digitorum superficialis with or without A1 pulley release. Hand (N Y). 2007;2(4):227-231. doi: 10.1007/s11552-007-9065-z. Epub 2007 Jul 26.

24. Ballantyne J, Hooper G. The hand and diabetes. CurrOrthop. 2004;18(2):118-125.doi: https://doi.org /10. 1016/j.cuor.2004.02.007

25. Fitzgerald BT, Setty A, Mudgal CS. Gout affecting the hand and wrist. J Am Acad Orthop Surg. 2007;15 (10) : 625-635.

26. Fahey JJ, Bollinger JA. Trigger-finger in adults and children. JBJS. 1954;36(6):1200-1218. 


\section{Original Research Article}

27. Newport ML, Lane LB, Stuchin SA. Treatment of trigger finger by steroid injection. J Hand Surg. 1990; 15 (5):748-750. doi: https://doi.org/10.1016/0363-5023 (90) $90149-\mathrm{L}$

28. Patel MR, Bassini L. Trigger fingers and thumb: when to splint, inject, or operate. J Hand Surg Am. 1992; 17 (1):110-113. doi:10.1016/0363-5023 (92) 90124-8

29. Weilby A. Trigger finger. Incidence in children and adults and the possibility of a predisposition in certain age groups. Acta Orthop Scand. 1970;41(4):419-427. doi:10.3109/17453677008991529

30.Freiberg A, Mulholland RS, Levine R. Nonoperative treatment of trigger fingers and thumbs. The Journal of hand surgery. $1989 ; 14(3)$ : 553-538. doi:10.1016/s03635023 (89)80024-3

31. Manske PR, Lesker PA. Flexor tendon nutrition. Hand Clinics. 1985;1(1):13-24.

32. Pope DF, Wolfe SW. Safety and efficacy of percutaneous trigger finger release. J Hand Surg Am. 1995; 20 (2): 280-283. doi: 10. 1016/S0363-5023 (05) 80026-7
33. Carrozzella J, Stern PJ, Von Kuster LC. Transection of radial digital nerve of the thumb during trigger release. J Hand Surg Am. 1989; 14(2 Pt 1):198-200. doi: 10.1016/0363-5023(89)90006-3.

34. Ranjeet N, Sapkota K, Thapa P, Onta PR, Wahegoankar K, Thapa UJ, et al. Trigger Finger: A Prospective Randomised Control Trial Comparing Percutaneous Release versus Open Release. J Clinic Diagnostic Res. 2018;12(7): RC05-RC08. doi: 10.7860/ JCDR/2018/34100.11771

35. Bain GI, Turnbull J, Charles MN, Roth JH, Richards RS. Percutaneous A1 pulley release: a cadaveric study. J Hand Surg Am. 1995;20(5):781-784; discussion 7856. doi:10.1016/S0363-5023(05)80430-7

36. Eastwood DM, Gupta KJ, Johnson DP. ercutaneous release of the trigger finger: an office procedure. J Hand Surg Am. 1992;17(1):114-117. doi:10.1016/0363-5023 (92) 90125-9

37. Lange-Riess D, Schuh R, Hönle W, Schuh A. Longterm results of surgical release of trigger finger and trigger thumb in adults. Arch Orthop Trauma Surg. 2009; 129 (12): 1617-1619. doi: 10.1007/s00402-0080802-8. Epub 2009 Jan 6.

\section{How to cite this article?}

Malviya V.K, Soni R.K. Percutaneous release of trigger finger without local anaesthesia as an outpatient procedure. Surgical Update: Int J surg Orthopedics. 2019;5(4):259-265.doi:10.17511/ijoso.2019.i04.05 